\title{
Effect of combination invasive intracranial pressure (ICP) monitoring and transcranial Doppler in the treatment of severe craniocerebral injury patients with decompressive craniectomy
}

\author{
Tao Jin", Weijie Lian", Ke Xu, Yan Liu, Zhennan Xu, Rongzhang Lu, Mingfa Liu \\ Department of Neurosurgery, Shantou Central Hospital, Affiliated Shantou Hospital of Sun Yat-sen University, Shantou, China \\ Contributions: (I) Conception and design: T Jin, W Lian; (II) Administrative support: M Liu; (III) Provision of study materials or patients: K Xu, Y \\ Liu; (IV) Collection and assembly of data: T Jin, Z Xu; (V) Data analysis and interpretation: R Lu, W Lian; (VI) Manuscript writing: All authors; \\ (VII) Final approval of manuscript: All authors. \\ \#These authors contributed equally to this work. \\ Correspondence to: Mingfa Liu. Department of Neurosurgery, Shantou Central Hospital, Affiliated Shantou Hospital of Sun Yat-sen University, \\ Waima Road No.114, Jinping District, Shantou 515041, China. Email: stlmf1163@sina.com.
}

\begin{abstract}
Background The aim of the present study was to explore the clinical effect and to predict the prognosis of severe craniocerebral injury patients with decompressive craniectomy by combining transcranial Doppler (TCD) and invasive intracranial pressure (ICP).

Methods: A total of 60 severe craniocerebral injury patients with decompressive craniectomy, who were admitted to Shantou Central Hospital from June 2017 to March 2019, were enrolled in this retrospective study. Of these, 25 patients who had a Glasgow Coma Scale (GCS) score no greater 8 and no less than 6 underwent transcranial Doppler (TCD) before decompressive craniectomy, as well as ICP, after removing the skull and suturing the dura mater. The 60 patients were divided into 2 groups according to the following standards: (I) GCS score $\geq 8$ on the 7th day postoperatively; (II) ICP continuously lower than $25 \mathrm{mmHg}$ for the entire 7-day duration postoperatively; and (III) brain tissue consistently offset from the skull surface by $5 \mathrm{~mm}$. The clinical outcome was determined based on the Glasgow Outcome Scale (GOS) 1, 3, and 6 months postoperatively. The TCD value, ICP, and prognosis were compared between the 2 groups.

Results: The average postoperative ICP $<19 \mathrm{mmHg}$ in the first $24 \mathrm{~h}$, mean blood flow velocity $>56.33 \mathrm{~cm} / \mathrm{s}$, end-diastolic blood flow velocity $>40.28 \mathrm{~cm} / \mathrm{s}$, and resistance index $<0.57$ were statistically significant indicators to predict good prognosis .
\end{abstract}

Conclusions: The use of TCD can predict the prognosis of severe craniocerebral injury patients.

Keywords: Invasive intracranial pressure (ICP); decompressive craniectomy; cranioplasty; transcranial Doppler (TCD); Glasgow Outcome Scale (GOS)

Submitted Jan 29, 2021. Accepted for publication Apr 01, 2021.

doi: 10.21037/apm-21-504

View this article at: http://dx.doi.org/10.21037/apm-21-504

\section{Introduction}

As one of the most common serious problem in neurosurgery, craniocerebral injury is associated with poor prognosis and high rates of mortality and disability. One of the main reasons for this is due to the cerebral hernia caused by high invasive intracranial pressure (ICP). Therefore, to improve prognosis and overall survival, it is important to remove the hematoma and reduce the ICP. Up until now, decompressive craniectomy has been regarded as the most effective treatment for severe craniocerebral injuries (1). Many neurosurgeons have found that the prognosis and life quality of craniocerebral injuries are significantly different; therefore the indication of decompressive craniectomy is controversial (2). There are some limitations of the Glasgow 
Table 1 Clinical data for both groups

\begin{tabular}{|c|c|c|}
\hline Clinical factor & Group A & Group B \\
\hline Age (years) & $26-70(45 \pm 7.3)$ & $22-61(43 \pm 5.6)$ \\
\hline Male & 14 & 22 \\
\hline Female & 9 & 15 \\
\hline ICP after dural tension suture $(\mathrm{mmHg})$ & $13.00 \pm 4.00$ & $25.00 \pm 7.00$ \\
\hline ICP 24 h postoperatively $(\mathrm{mmHg})$ & $19.00 \pm 3.00$ & $28.00 \pm 6.00$ \\
\hline ICP $72 \mathrm{~h}$ postoperatively ( $\mathrm{mmHg}$ ) & $17.00 \pm 4.00$ & $24.00 \pm 4.00$ \\
\hline ICP 7 days postoperatively $(\mathrm{mmHg})$ & $16.00 \pm 3.00$ & $22.00 \pm 3.00$ \\
\hline
\end{tabular}

ICP, invasive intracranial pressure.

Coma Scale (GCS), such as subjective and lack of weight in the three parts of the scale, thus, evaluation during the perioperative period is not exactly accurate. Cranioplasty with special material is a heavy financial burden for many people in development country. Therefore, an indicator for predicting the possibility to accept the real-time cranioplasty with the original skull after removing the hematoma could effectively improve patients' quality of life (3). To explorer how do some of the preoperative factors influence the prognosis of decompressive craniectomy, we retrospectively analyzed 60 craniocerebral cases between June 2017 and March 2019 at the Shantou Central Hospital using transcranial Doppler (TCD) and ICP monitoring. We present the following article in accordance with the STROBE reporting checklist (available at http://dx.doi. org/10.21037/apm-21-504).

\section{Methods}

\section{Clinical data}

Between June 2017 and March 2019, 60 craniocerebral patients at the Shantou Central Hospital (36 males and 24 female, age 21-70 years) without multiple trauma, multiple organ failure, and moribund condition, who were admitted to Shantou Central Hospital were included in the present study. All patients were alive 6 months postoperatively. The patients were divided into 2 groups according to the following standards: (I) GCS score $\geq 8$ on the 7 th day postoperatively; (II) ICP continuously lower than $25 \mathrm{mmHg}$ for the entire 7-day duration postoperatively; and (III) brain tissue consistently offset from the skull surface by $5 \mathrm{~mm}$ in the postoperative computed tomography (CT) scan. The clinical outcome was determined based on the Glasgow Outcome Scale (GOS) 1, 3, and 6 months postoperatively. Group A included patients who met all the standards, whereas Group B included patients who did not (Table 1). The study was conducted in accordance with the Declaration of Helsinki (as revised in 2013). The study was approved by Shantou Central Hospital (No.[2017]Scientific Research-001). Written informed consent was provided by all participants.

\section{TCD}

All the patients were treated by decompressive craniectomy. Twenty-five patients were randomly selected for TCD after perform a craniotomy and open the skull. All patients underwent TCD examination, including evaluation by using transcranial Doppler machine named TC 2020 Pioneer (EME). Systolic peak flow velocity (Vs), end-diastolic flow velocity $(\mathrm{Vd})$, mean peak flow velocity $(\mathrm{Vm})$, pulsatility index $[\mathrm{PI}=(\mathrm{Vs}-\mathrm{Vd}) / \mathrm{Vm}]$, and resistance index $[\mathrm{RI}=(\mathrm{Vs}-$ $\mathrm{Vd}) / \mathrm{Vs}$ ] was recorded. The ICP was detected after the dural recession, and after the dural tension suture by the Codman ICP Monitor (Codman, Miami, United States). The postoperative CT scan was completed by Siemens 64 Slices Single Source CT Scanner (GE, United States).

\section{Parameters and statistical analysis methods}

TCD and CT scan results; ICP value 24 h postoperatively; 
Table 2 Hemodynamic parameters after removing the skull $(\bar{x} \pm s)$

\begin{tabular}{lcccccc}
\hline Group & $\mathrm{n}$ & $\mathrm{Vs}(\mathrm{cm} / \mathrm{s})$ & $\mathrm{Vm}(\mathrm{cm} / \mathrm{s})$ & $\mathrm{Vd}(\mathrm{cm} / \mathrm{s})$ & $\mathrm{Rl}$ & $\mathrm{PI}$ \\
\hline A & 11 & $125.06 \pm 22.11$ & $72.31 \pm 14.49$ & $52.62 \pm 10.34$ & $0.58 \pm 0.08$ & $1.44 \pm 0.35$ \\
B & 14 & $116.12 \pm 24.11$ & $40.30 \pm 12.95$ & $25.66 \pm 8.89$ & $0.76 \pm 0.09$ & $1.78 \pm 0.62$ \\
\hline
\end{tabular}

Vs, systolic peak flow velocity; Vm, mean peak flow velocity; Vd, end-diastolic flow velocity; RI, resistance index; PI, pulsatility index.

Table 3 Reported complications of 60 patients on the 7 th postoperative day

\begin{tabular}{lcc}
\hline Complications & Group A, n (\%) & Group B, n (\%) \\
\hline Shock & $5(21.74)$ & $13(35.14)^{\star}$ \\
Delayed intracranial hematoma & $3(13.04)$ & $8(21.62)^{\star}$ \\
Subdural hygroma & $0(0.00)$ & $6(16.22)^{\star}$ \\
Intracranial infection & $0(0.00)$ & $1(2.70)$ \\
Seizures & $4(17.40)$ & $9(24.33)^{\star}$ \\
Surgical wound healing delayed & $0(0.00)$ & $0(0.00)$ \\
hydrocephalus & $0(0.00)$ & $0(0.00)$ \\
\hline
\end{tabular}

*, $(\mathrm{P}<0.05)$ between the 2 groups.

GCS score; complications at day 7, 1 month, 3 months, and 6 months postoperatively; and GOS were recoded. SPSS version 22.0 (IBM, Armonk, NY, USA) was used to analyze all parameters; $t$-test was used for the measurement data, and $\chi^{2}$-test was used for enumeration data. $\mathrm{P}<0.05$ indicated statistical significance. No missing data in this study.

\section{Results}

\section{Hemodynamic parameters of the 25 patients who underwent TCD scan}

Hemodynamic parameters were compared between both groups. The Vm, Vd, RI, GCS score $=8$, ICP after dural tension suture $(\mathrm{mmHg})$, and ICP 24 h postoperatively $(\mathrm{mmHg})$ were statistically significant, whereas Vs and PI were not (Table 2).

\section{Complications of the 60 patients on the 7 th postoperative day}

Shock, delayed intracranial hematoma, and subdural hygroma were statistically different in the 2 groups, while intracranial infection, seizures, surgical wound healing delay, and hydrocephalus were not (Table 3).

\section{Complications of 25 patients who underwent TCD on the 7th postoperative day}

There was a statistically significant difference in shock between the 2 groups, indicating that the parameters of this group could be regarded as a contraindication of real-time cranioplasty (Table 4).

\section{Complications and the GOS score of the 60 patients in the 6 th postoperative month}

Shock, delayed intracranial hematoma, subdural hygroma, seizures, hydrocephalus, total complications, GOS score in the 1 st month, GOS score in the $3 \mathrm{rd}$ month, and GOS score in the 6th month were statistically different between the groups $(\mathrm{P}<0.05)$, while intracranial infection and surgical wound healing delayed were not $(\mathrm{P}>0.05)$, indicating that our standards can effectively predict poor prognosis. Therefore, patients with poor prognosis should be given radical treatment (Table 5).

\section{Complications and the GOS score of 25 patients who underwent TCD scan in the 6th postoperative month}

There was a statistically significant difference in shock, subdural hygroma, total complications, GOS score in the 1 st month, GOS score in the 3rd month, and GOS score in the 6th month between the 2 groups (Table 6).

\section{Discussion}

Severe craniocerebral injury is a disease with high mortality and disability. Therefore, it is meaningful to come out with a new protocol to deter the personal treatment. The main reason account for the death is the exorbitant ICP, therefore, as an effective was to reduce ICP, decompressive craniectomy was widely used in lots of disease with high ICP such as severe craniocerebral injury and massive 
Table 4 Reported complications of 25 patients who underwent transcranial Doppler scan on the 7th postoperative day

\begin{tabular}{|c|c|c|c|c|}
\hline Complications & \multicolumn{2}{|c|}{ Group A, n (\%) } & \multicolumn{2}{|c|}{ Group B, n (\%) } \\
\hline Shock & $2(18.18)$ & $1(12.5)$ & $5(35.71)$ & $1(25.00)$ \\
\hline Delayed intracranial hematoma & $1(9.09)$ & $1(12.5)$ & $3(21.43)$ & $0(0.00)$ \\
\hline Subdural hygroma & $0(0.00)$ & $0(0.00)$ & $3(21.43)$ & $0(0.00)$ \\
\hline Seizures & $2(18.18)$ & $0(0.00)$ & $4(28.58)$ & $1(25.00)$ \\
\hline Surgical wound healing delayed & $0(0.00)$ & $0(0.00)$ & $0(0.00)$ & $0(0.00)$ \\
\hline hydrocephalus & $0(0.00)$ & $0(0.00)$ & $0(0.00)$ & $0(0.00)$ \\
\hline
\end{tabular}

Table 5 Reported complications and the Glasgow Outcome Scale (GOS) scores of the 60 patients 6 months postoperatively

\begin{tabular}{lcc}
\hline Complications & Group A & Group B \\
\hline Shock, n (\%) & $5(21.74)$ & $14(37.84)^{\star}$ \\
Delayed intracranial hematoma, n (\%) & $2(7.69)$ & $5(13.51)$ \\
Subdural hygroma, $\mathrm{n}(\%)$ & $6(26.09)$ & $16(43.24)^{\star}$ \\
Intracranial infection, $\mathrm{n}(\%)$ & $1(4.35)$ & $1(2.70)$ \\
Seizures, $\mathrm{n}(\%)$ & $2(8.70)$ & $5(13.51)^{\star}$ \\
Surgical wound healing delayed, $\mathrm{n}(\%)$ & $0(0.00)$ & $0(0.00)$ \\
Hydrocephalus & $4(17.39)$ & $13(35.14)$ \\
GOS score in the 1st month & $4.1 \pm 0.3$ & $3.2 \pm 0.6$ \\
GOS score in the 3rd month & $4.6 \pm 0.2$ & $3.7 \pm 0.3$ \\
GOS score in the 6th month & $4.9 \pm 0.3$ & $4.1 \pm 0.4$ \\
\hline
\end{tabular}

*, $(\mathrm{P}<0.05)$ between the 2 groups.

stroke since 1901 (4). With a hundred years application, neurosurgeons believe that patients can be benefit from the ICP reducing and the improvement of blood supplement in the peri-sylvian area, reducing the rate of mortality. However, the operation can lead to seizures, trephination, and paradoxical herniation, which reduce patients' quality of life (2,5). Emergency cranioplasty, or real-time cranioplasty, can be a solution for some patients to avoid these complications (6). Moreover, because of the operation gap, some doctors cannot do the standard large craniectomy decompression correctly. In these cases, patients suffer from the insufficient decompression and rebleeding partly caused by the undersized bone flap and incomplete removal of the spina ossis sphenoid (7). The ICP of some patients can be reduced to $30 \%$ of preoperative or normal level after incising the dura mater. The postoperative CT scan at $24 \mathrm{~h}$ showed that the brain tissue was lower than $5 \mathrm{~mm}$ above the skull bone, indicating a low possibility of cerebral hernia. This can be regarded as the physiological fundamental of real-time cranioplasty (1). Patients can avoid complications, as well as reduce the financial burden of elective cranioplasty by real-time cranioplasty (8). Furthermore, one of the potential reasons to explain that real-time cranioplasty can lead to a better prognosis is that these patients have less seizure-related factors course by the delay cranioplasty such as syndrome of trephined (2).

In our study, the grouping system based on postoperative ICP combining with GCS score and CT scans can be used to predict long-term complications in severe craniocerebral injury patients. The TCD and preoperative GCS score can 
Table 6 Reported complications and the Glasgow Outcome Scale (GOS) scores of the 25 patients who underwent transcranial Doppler scan 6 months postoperatively

\begin{tabular}{|c|c|c|c|c|}
\hline Complications & \multicolumn{2}{|c|}{ Group A } & \multicolumn{2}{|c|}{ Group B } \\
\hline Shock, n (\%) & $2(18.18)$ & $1(12.5)$ & $5(35.71)$ & $1(25.00)$ \\
\hline Delayed intracranial hematoma, n (\%) & $1(9.09)$ & $1(12.5)$ & $3(21.43)$ & $0(0.00)$ \\
\hline Subdural hygroma, n (\%) & $0(0.00)$ & $0(0.00)$ & $3(21.43)$ & $0(0.00)$ \\
\hline Seizures, n (\%) & $2(18.18)$ & $0(0.00)$ & $4(28.58)$ & $1(25.00)$ \\
\hline Surgical wound healing delayed, n (\%) & $0(0.00)$ & $0(0.00)$ & $1(7.14)$ & $0(0.00)$ \\
\hline Hydrocephalus, n (\%) & $0(0.00)$ & $0(0.00)$ & $0(0.00)$ & $0(0.00)$ \\
\hline GOS score in the 1st month & $4.1 \pm 0.2$ & $4.2 \pm 0.2$ & $3.1 \pm 0.5$ & $3.4 \pm 0.3$ \\
\hline
\end{tabular}

Pre-op, pre-operation.

be used as short- and long-term complication indicators, as well as potential indicators, to diagnose real-time cranioplasty patients.

ICP monitoring is highly recommended for brain traumatic treatment and has been confirmed in several randomized controlled trials and guidelines $(9,10)$. However, controversy still exists regarding the duration of ICP monitoring. The findings of the present indicated that the first $24 \mathrm{~h}$ of ICP monitoring are particularly important for evaluating the prognosis and can be used as a short-term complication indicator. There is a significant different outcome of mean ICP in $19.00 \pm 3.00 \mathrm{mmHg}$ (groups A and B). In the previous hypothesis, there is a threshold ICP in the early stage of brain trauma $(11,12)$. The damage of neurons and glia cells is different above or below the threshold. There are many adjustment factors that are used to control postoperative ICP such as mannitol, hypertonic saline, and albumin (13). However, the inappropriate use of mannitol will lead to a poor prognosis like renal failure. Therefore, it is important to downregulate the postoperative ICP according to ICP monitoring during treatment (14).

TCD is a convenient and non-invasive test. It is an exploratory job to choose the operation method based on the TCD (15). In the present study, we found that patients with $\mathrm{Vm}>56.33 \mathrm{~cm} / \mathrm{s}, \mathrm{Vd}>40.28 \mathrm{~cm} / \mathrm{s}$, RI $<0.57$, preoperative GCS score $=8$, and ICP $24 \mathrm{~h}$ after operation $<19 \mathrm{mmHg}$ had a good prognosis. The findings indicated that there should be some optimization in the indications of decompressive craniectomy. Notably, there was no statistical difference in the PI between the 2 groups. The $\mathrm{PI}$ is an objective factor in reflecting the situation of blood supplement. Therefore, observation of the brain pulse before dural tension suture should no longer be the prognosis indicator. Brain pulse disappearance was once regarded as the predictor of cerebral infarction.

Recently, some neurosurgeons believe that patients can be benefit from some invasive operation like internal decompression in downregulating the ICP because the complications of decompressive craniectomy (16). But these operations is lack of evidence in brain trauma; therefore, standard large craniectomy decompression is the most useful strategy. Because of the sample limitations and the limitations of prognosis factors which cannot shows the outcome comprehensively, our study can be regarded as an observation in discussing the possibility of some patients who may be benefit from normal craniectomy decompression and real-time cranioplasty rather than challenge the importance of standard large craniectomy decompression in the therapeutic protocol of severe craniocerebral injury.

\section{Conclusions}

Decompressive craniectomy was once regarded the most useful treatment for severe craniocerebral injury. However, the findings of our study indicate that with the use of ICP 
monitoring and TCD, some patients could be potentially treated in a less invasive way, furthermore, the accurately indicators of real-time cranioplasty can be further discussed.

\section{Acknowledgments}

Funding: This study was funded by the Science and Technology Bureau of Shantou City (No. Shanfuke2018-11-5).

\section{Footnote}

Reporting Checklist: The authors have completed the STROBE reporting checklist. Available at http://dx.doi. org/10.21037/apm-21-504

Data Sharing Statement: Available at http://dx.doi. org/10.21037/apm-21-504

Conflicts of Interest: All authors have completed the ICMJE uniform disclosure form (available at http://dx.doi. org/10.21037/apm-21-504). The authors have no conflicts of interest to declare.

Ethical Statement: The authors are accountable for all aspects of the work in ensuring that questions related to the accuracy or integrity of any part of the work are appropriately investigated and resolved. The study was conducted in accordance with the Declaration of Helsinki (as revised in 2013). The study was approved by Shantou Central Hospital (No.[2017]Scientific Research-001). Written informed consent was provided by all participants.

Open Access Statement: This is an Open Access article distributed in accordance with the Creative Commons Attribution-NonCommercial-NoDerivs 4.0 International License (CC BY-NC-ND 4.0), which permits the noncommercial replication and distribution of the article with the strict proviso that no changes or edits are made and the original work is properly cited (including links to both the formal publication through the relevant DOI and the license). See: https://creativecommons.org/licenses/by-nc-nd/4.0/.

\section{References}

1. Yamaura A, Uemura K, Makino H. Large decompressive craniectomy in management of severe cerebral contusion. A review of 207 cases. Neurol Med Chir (Tokyo) 1979;19:717-28.
2. Barthélemy EJ, Melis M, Gordon E, et al. Decompressive Craniectomy for Severe Traumatic Brain Injury: A Systematic Review. World Neurosurg 2016;88:411-20.

3. Stoner KE, Abode-Iyamah KO, Grosland NM, et al. Volume of Brain Herniation in Patients with Ischemic Stroke After Decompressive Craniectomy. World Neurosurg 2016;96:101-6.

4. Honeybul S, Ho KM, Lind CRP, et al. The current role of decompressive craniectomy for severe traumatic brain injury. J Clin Neurosci 2017;43:11-5.

5. Alvis-Miranda H, Castellar-Leones SM, Moscote-Salazar LR. Decompressive Craniectomy and Traumatic Brain Injury: A Review. Bull Emerg Trauma 2013;1:60-8.

6. Nasi D, Dobran M, Iacoangeli $M$, et al. Paradoxical Brain Herniation After Decompressive Craniectomy Provoked by Drainage of Subdural Hygroma. World Neurosurg 2016;91:673.e1-4.

7. Jasey N, Ward I, Lequerica A, et al. The therapeutic value of cranioplasty in individuals with brain injury. Brain Inj 2018;32:318-24.

8. Corallo F, De Cola MC, Lo Buono V, et al. Early vs late cranioplasty: what is better? Int J Neurosci 2017;127:688-93.

9. Hawryluk GWJ, Rubiano AM, Totten AM, et al. Guidelines for the Management of Severe Traumatic Brain Injury: 2020 Update of the Decompressive Craniectomy Recommendations. Neurosurgery 2020;87:427-34.

10. Abraham P, Rennert RC, Gabel BC, et al. ICP management in patients suffering from traumatic brain injury: a systematic review of randomized controlled trials. Acta Neurochir (Wien) 2017;159:2279-87.

11. Helbok R, Meyfroidt G, Beer R. Intracranial pressure thresholds in severe traumatic brain injury: Con : The injured brain is not aware of ICP thresholds! Intensive Care Med 2018;44:1318-20.

12. Honda M, Ichibayashi R, Suzuki G, et al. Consideration of the Intracranial Pressure Threshold Value for the Initiation of Traumatic Brain Injury Treatment: A Xenon CT and Perfusion CT Study. Neurocrit Care 2017;27:308-15.

13. Cook AM, Jones GM, Hawryluk GWJ, et al. Guidelines for the Acute Treatment of Cerebral Edema in Neurocritical Care Patients. Neurocrit Care 2020;32:647-66.

14. Chang T, Li L, Yang Y, et al. Transcranial Doppler Ultrasonography for the Management of Severe Traumatic Brain Injury After Decompressive Craniectomy. World Neurosurg 2019;126:e116-24. 
15. Daboussi A, Minville V, Leclerc-Foucras S, et al. Cerebral hemodynamic changes in severe head injury patients undergoing decompressive craniectomy. J Neurosurg Anesthesiol 2009;21:339-45.

16. Kolias AG, Viaroli E, Rubiano AM, et al. The current

Cite this article as: Jin T, Lian W, Xu K, Liu Y, Xu Z, Lu R, Liu M. Effect of combination invasive intracranial pressure (ICP) monitoring and transcranial Doppler in the treatment of severe craniocerebral injury patients with decompressive craniectomy. Ann Palliat Med 2021;10(4):4472-4478. doi: 10.21037/apm-21-504 status of decompressive craniectomy in traumatic brain injury. Curr Trauma Rep 2018;4:326-32.

(English Language Editor: R. Scott) 